\title{
Gelişimsel kalça displazisi tedavisinde Salter osteotomisi
}

\author{
Salter osteotomy in the treatment of developmental dysplasia of the hip \\ Serkan Sipahioğlu*, Hüseyin Aşkar, Sinan Zehir, Uğur Erdem Işıkan
}

Ortopedi ve Travmatoloji Anabilim Dalı (Yrd. Doç. S. Sipahioğlu, Prof. Dr. U. E. Işıkan), Harran Üniversitesi Tıp Fakültesi, TR-63300 Şanlıurfa, Ortopedi Kliniği (Dr. H. Aşkar), Samandağ Devlet Hastanesi, TR-31770 Hatay, Ortopedi ve Travmatoloji Anabilim Dalı (Yrd. Doç. S. Zehir), Hitit Üniversitesi Tıp Fakültesi, TR-19040 Çorum

\begin{abstract}
Özet
Amaç. Gelişimsel kalça displazisi bulunan olgularda Salter pelvik osteotomi uygulaması sonrası erken dönem sonuçlarını radyolojik ve klinik olarak değerlendirmek. Yöntem. Kliniğimize 2002 2008 yılları arasında başvuran ve daha önce herhangi bir tedavi uygulanmamış GKD tanısı konmuş, açık redüksiyon ve Salter İnnominate osteotomi ile tedavi edilmiş 51 kalça (44 hasta,12 erkek, 32 kız, ortalama yaş 30,7 ay) ortalama 25 aylık takip sonucunda retrospektif olarak değerlendirildi. Olgular klinik olarak McKay sınıflamasına, radyolojik olarak Severinin kriterlerine ve avasküler nekroz (AVN) varlığı ise Kalamchi-MacEwen kriterlerine göre değerlendirildi. Bulgular. Preoperatif asetabular indeksi ortalama 37,4 (29-50) derece olan hastaların en son takibi sırasında alınan postoperatif asetabular indeks değerleri ortalama 24,1 (1232) derece bulundu. MacKay in klinik değerlendirme sistemine göre 51 kalçanın 43’ü (\%84) mükemmel, 7'si $(\% 13,7)$ iyi, 1'i (\%2) orta idi. Severinin radyolojik sınıflamasına göre 26 kalça (\%51) çok iyi, 15 kalça $(\% 29,4)$ iyi, 8 kalça $(\% 15,7)$ orta ve 2 kalça $(\% 3,9)$ kötü olarak değerlendirildi Postoperatif AVN oranı yaklaşık \%17,6 (9 kalça) idi. Sonuç. Onsekiz ay sonrası GKD tedavisinde Salter innominate osteotomisi etkin bir yöntem olarak pelvis osteotomisi seçenekleri arasında değerlendirilebilir. İleri yaşlarda artan komplikasyon riskini düşürmek için osteotomi tekniğine uygun yapılmalıdır.
\end{abstract}

Anahtar sözcükler: Kalça çıkığı, doğumsal, osteotomi

\begin{abstract}
Aim. We evaluated the short-term results of Salter pelvic osteotomy for the treatment of developmental dysplasia of the hip (DDH). Methods. Forty four patients (32 girls, 12 boys; mean age 30.7months) with DDH underwent Salter innominate osteotomies in 51 hips were evaluated retrospectively. Clinical evaluations were made according to the McKay criteria, radiologic assessment was made using Severin criteria and avascular necrosis of the femoral head was assessed using the Kalamchi-MacEwen criteria. The mean follow-up period was 25 month. Results. The mean acetabular index which was 37.40 (29-50) preoperatively decreased to 24.10 (12-32) postoperatively. Clinical results were excellent in 43 hips (84\%), good in $7(13.7 \%)$ and moderate in one $(2 \%)$ patient. 26 hips $(51 \%)$ were excellent, 15 hips $(29.4 \%)$ were good, 8 hips $(15.7 \%)$ were moderate and 2 hips $(3.9 \%)$ were bad according to Severin radiologic classification. According to the Kalamchi-MacEwen criteria, there was avascular necrosis in nine hips (17.6\%) postoperatively. Conclusion. Salter innominate osteotomy can be evaluated as one of the effective method among pelvic osteotomies in the treatment of DDH patients older than eghteen years old.For reducing complication risk which increases age osteotomy should be done in a proper technique.
\end{abstract}

Keywords: Hip dislocation, congenital; osteotomy

Geliş tarihi/Received: 13 Şubat 2014; Kabul tarihi/Accepted: 04 Aralık 2014

\section{*İletişim adresi:}

Dr. Serkan Sipahioğlu, Ortopedi ve Travmatoloji Anabilim Dalı, Harran Üniversitesi Tıp Fakültesi, TR-63300 Şanlıurfa. E-posta: drserkans@ gmail.com 


\section{Giriş}

Ülkemizde \%5,9 gibi yüksek bir prevelansa sahip olan gelişimsel kalça displazisi (GKD) prognozunda erken tanı ve tedavi hala anahtar rol oynamaktadır [1]. GKD tedavisinde amaç konsantrik redüksiyon, asetabular bozukluğun ve patolojik yapıların düzeltilmesi ile stabil ve uyumlu bir kalça eklemi sağlayarak erken dejeneratif artrit gelişimin önlemektir. Asetabulumdaki sığlık ve yönelim bozukluğu erken çocukluk döneminde düzeltilirse femur başı asetabulum ile örtünerek yeniden şekillenme sayesinde uyumlu bir kalça eklemi elde edilebilir [2]. GKD'de yaşamın ilk yılı asetabulum ve femur başı gelişimi için en değerli dönemdir. On sekiz aya kadar yapılacak kapalı veya açık redüksiyon meydana gelebilecek olası tedavi komplikasyonlarını özellikle avasküler nekroz (AVN) oranını düşürmektedir [3]. On sekiz aydan sonra çoğunlukla bozuk olan asetabular yapıya müdahale edilmeden karalı bir eklem elde etmek mümkün olamamaktadır [4]. Bu nedenle bu yaş grubunda tedaviye pelvik osteotomiler de eklenmelidir.

Salter'in 1961 'de tanımladig1, innominat kemik osteotomisi asetabulum seklini ve hacmini degistirmeden oryantasyonunu degistirerek, asetabulumun yük binen alanını artırır ve bu da asetabulum gelisimini olumlu etkiler [5]. Salter kalça çıkıklarının birçoğunda asetabulum tavanının anterior, superior ve lateral kenarında yapısal gelişme kusuru olduğunu ve bu nedenle osteotomi sonrasında distal parçayı pubis etrafında anteriora, laterale ve inferiora döndürerek asetabulumu femur başını örtecek konuma getirmeyi önermiştir [5]. Geçen yıllarda Salter osteotomisinin etkinliği kanıtlanarak klasik tedavi yöntemleri arasındaki yerini almıştır [2].

$\mathrm{Bu}$ çalışmada kliniğimize geç başvuran, açık redüksiyon (AR) ve Salter pelvik osteotomisi (SİO) ile tedavi edilen hastaların AVN oranları ile birlikte radyolojik ve klinik sonuçlarımızı sunmayı amaçladık

\section{Gereç ve yöntem}

GKD öntanısıyla 2002-2008 yılları arasında kliniğimize başvuran ve yapılan klinik ve radyolojik muayene sonrasında AR+SIO ile tedavi edilen 44 hastanın 51 kalçası geriye dönük olarak değerlendirildi. Hastaların en az bir yıl takip süresi olması ölçüt olarak alındı. 44 hastanın 12'si (\%27 ) erkek, 32'si (\%73) kız idi. Bu hastaların 7'si (\%15) bilateral, 37'si (\%85) tek taraflıydı. Tek taraflı 37 hastanın 27'sinde (\%72) sol, 10'nunda (\%28) sağ kalçada displazi tespit edildi (Tablo 1). Ortalama yaş 30,73 $\pm 12,3$ ay, ortalama takip süresi 25,39 $\pm 13,6$ (13-78) ay idi. Opere edilen kalçaların 34'ü sol, 17'si sağ kalça idi.

\section{Tablo 1. Hastaların kalça taraf ve cinsiyetlerine göre dağılımı.}

\begin{tabular}{lllllll}
\hline Hasta Taraf & \multicolumn{2}{l}{ Erkek } & Kız & \multicolumn{3}{c}{ Toplam } \\
\cline { 2 - 7 } & Sayı & \% & Sayı & \% & Sayı & \% \\
\hline Sol kalça & 5 & 41,6 & 22 & 68,7 & 27 & 61,3 \\
Sağ kalça & 5 & 41,6 & 5 & 15,6 & 10 & 22,7 \\
Bilateral & 2 & 16,6 & 5 & 15,6 & 7 & 15,9 \\
\hline Toplam & $\mathbf{1 2}$ & $\mathbf{1 0 0}$ & $\mathbf{3 2}$ & $\mathbf{1 0 0}$ & $\mathbf{4 4}$ & $\mathbf{1 0 0}$ \\
\hline
\end{tabular}

Tüm olguların operasyon öncesi ve son kontrollerde asetabular açıları (AC) ve CE açıları ölçüldü. Yalnız operasyon öncesi CE açısı, tam çıkık nedeniyle ölçülemeyen olguların fazlalığı nedeniyle değerlendirme kapsamına alınmadı.

Tüm kalçalarda adduktor tenotomi, iliopsoas tendonu gevsetilmesi, açık redüksiyon, SİO aynı seansta yapıldı. İlk olarak medialden transvers kesiyle adduktor longus tendonu gevsetildi. Sonra anterolateralden, Smith-Peterson kesisi ile girildi. Sartorius-tensor fascia klivaj1 kullanılarak rectus uzun bası tenotomisi ve sonra iliopsoas tendonu gevsetilmesi yapıldı. Kapsül açılarak, ligamentum teres ve pulvinar eksize edildi ve ligamentum transversum radial kesildi. Sonra kalça eklemi redükte edildi ve femur bası ile asetabulumun uyumu ve gerginliği degerlendirildi. Kalça eklemi redükte pozisyondayken femur basının anterolateral örtünme yetersizligi gösterdigi ve posterior asetabular 
yetmezligin olmadıgı tüm olgularda SİO yapıldı ve iliak kanattan alınan kemik grefti osteotomi hattına yerlestirilerek 2 adet K-teliyle tespit edildi. Superior kapsül eksize edilerek eklem kapsülü yeterli gerginlikte kapsulorafi yapıldı. Eklem kapsülünün onarılmasını takiben kalça ekleminin stabilitesi ve emniyetli hareket genisligi değerlendirilerek bu sınırlar içinde uygun pozisyonunda olacak şekilde 6 hafta pelvipedal alçıya alındı. Alçı açılması sonrası 6 hafta daha Ponseti cihazı uygulandı ve sonrasında serbest birakılarak takibe alındı.

Son kontrollerde hastaların klinik olarak, ağrı ve eklem hareket açıklıkları değerlendirildi. Trendelenburg yürüyüşüne bakıldı ve bu veriler McKay klinik değerlendirme metoduna göre sinıflandırıldı [6] (Tablo 2).

Tablo 2. Modifiye MacKay klinik değerlendirme kriterleri.

\begin{tabular}{|c|c|c|}
\hline Grup 1 & iyi & $\mathrm{Ha}$ \\
\hline Grup 2 & İyi & yok, hafif topallama var. Trendelenburg negatif Hareketler hafif kısıtlı \\
\hline Grup 3 & Orta & $\begin{array}{l}\text { Ağrı yok veya hafif. Trendelenburg pozitif veya negatif. Topallama ve orta } \\
\text { derecede hareket kaybı var }\end{array}$ \\
\hline Grup 4 & Kötü & $\begin{array}{l}\text { Ağr1 var, trendelenburg pozitif. Topallama ve ileri derecede hareket kayb1 } \\
\text { mevcut. }\end{array}$ \\
\hline
\end{tabular}

Radyolojik olarak da Severin'in sınıflama sistemi kullanılarak değerlendirme yapıldı ve grafileri çekilerek hastaların asetabular indeksleri ölçüldü [7] (Tablo 3). Avasküler nekroz bulgularının varlığı Kalamchi ve MacEwen'ın değerlendirme sistemine göre 3 ayrı gözlemci tarafından değerlendirilerek kaydedildi [8] (Tablo 4).

Tablo 3. Severin radyolojik değerlendirme kriterleri.

\begin{tabular}{llll}
\hline Grup 1 & Çok iyi & Normal kalça & CE açısı erişkinde $>25$, \\
Grup 2 & İyi & Femur başı, boynu ve asetabulumda hafif deformite & 6-13 yaş arası $>19$ \\
& & CE açıs erişkinde $>20-$ & $25,6-13$ yaş arası $>15$ \\
Grup 3 & Orta & $\begin{array}{l}\text { Displazik kalça, subluksasyon yok, baş ve boyun } \\
\text { hafif deforme }\end{array}$ & CE açısı erişkinde $<20$, \\
& & 6-13 yaş arası $<15$ \\
Grup 4 & Kötü & Subluksasyon & CE açıs $<5$ veya negatif \\
Grup 5 & Kötü & Yalancı asetabulumla eklem & \\
Grup 6 & Kötü & Redislokasyon & \\
\hline
\end{tabular}

Tablo 4. Kalamchi ve MacEwen'in avasküler nekroz değerlendirme ölçütleri.

\begin{tabular}{ll}
\hline Grup & Radyografik görünüm \\
\hline I & Kemikleşme merkezinde değişiklikler \\
II & Tip I+lateral fizis hasarı \\
III & Tip I+Santral fizis hasarı \\
IV & Tip I+Tüm fizis hasarı \\
\hline
\end{tabular}

Asetabular indeksin ameliyat öncesi ve ameliyat sonrası değişimi istatistiksel olarak değerlendirildi. Değerlendirmede parametrik olmayan Wilcoxon testi kullanıldı. Değerlendirme PASW Statistics 18 (for Windows) deneme sürümü kullanılarak yapıldı. $\mathrm{P}<0,05$ değerleri anlamlı olarak kabul edildi.

\section{Bulgular}

Çalışmaya aldığımız 44 hastanın 51 kalçası son kontrollerinde Mc Kay klinik değerlendirme kriterlerine göre değerlendirildi. Bu değerlendirmeye göre 43 kalça $(\% 84,3)$ Grup I (çok iyi), 7 kalça (\%13,7) Grup II (iyi), 1 kalça(\%2) Grup III (orta) olarak bulundu. Radyolojik değerlendirmede ise Severin kriterlerine göre 26 kalça (\%51) Grup I (çok iyi), 15 kalça $(\% 29,4)$ Grup II (iyi), 8 kalça $(\% 15,7)$ Grup III (orta), 2 kalça $(\% 3,9)$ grup IV (kötü) olarak değerlendirildi (Tablo 5). 
Tablo 5. Hastaların klinik ve radyolojik değerlendirme sonuçları.

\begin{tabular}{lllll}
\hline & Grup 1 & Grup 2 & Grup 3 & Grup 4 \\
\cline { 2 - 5 } & Mükemmel & İyi & Yeterli & Kötü \\
\hline Severin (radyolojik) & $26(\% 51)$ & $15(\% 29,4)$ & $8(\% 15,7)$ & $2(\% 3,9)$ \\
McKay (klinik) & $43(\% 84,3)$ & $7(\% 13,7)$ & $1(\% 2)$ & - \\
\hline
\end{tabular}

Postoperatif dönemde 18 olguda komplikasyon gelişti. Bu komplikasyonlar 3 vakada görülen yüzeyel enfeksiyon, 1 vakada görülen redislokasyon, 9 vakada görülen avasküler nekroz ve 5 vakada görülen hareket kisitlılığı idi (Tablo 6).

Tablo 6. Açık redüksiyon ve SİO sonrası görülen komplikasyonlar ve tüm hastalar içerisinde oranı.

\begin{tabular}{lll}
\hline Komplikasyonlar & Sayı & \% \\
\hline Avasküler Nekroz & 9 & 20,4 \\
Yüzeyel enfeksiyon & 3 & 6,8 \\
Redislokasyon & 1 & 2,2 \\
Hareket Kısıtlılığı & 5 & 11,3 \\
\hline Toplam & $\mathbf{1 8}$ & $\mathbf{4 0 , 9}$ \\
\hline
\end{tabular}

Avasküler nekroz gelişen hastaların yaşlarına bakıldığında bu hastaların tümünün serinin yaş ortalamasının üstünde kalan olgular olduğu görüldü. Kalamchi-MacEwen avasküler nekroz siniflamasina (Tablo 4) göre 6 hasta tip 1, 2 hasta tip 2 ve bir hasta tip 1 olarak değerlendirildi.

Hastalarda gelişen enfeksiyonların tamamı yüzeyel, kendini sınırlayan enfeksiyon olgularıydı. Bu hastalar kısa süreli antibiyotik tedavisi verilerek takibi yapıldı, tamamında düzelme sağland. Takip döneminde redislokasyon görülen 1 vakaya ise cerrahi olarak aç`k redüksiyon ve kapsulografi yapıldı, takiplerinde yeni bir komplikasyon gelişmedi.

Asetabular indeks preoperatif ortalama $37,4^{0} \pm 5,3\left(29^{0}-50^{0}\right)$ iken son kontrollerde ise ortalama $24,2^{0} \pm 4,9\left(12^{0}-32^{0}\right)$ olarak ölçüldü. Operasyon sonrası açısal düzelme ortalama $13,1^{0} \pm 7,3$ bulundu.

\section{Tartışma}

Gelişimsel kalça displazisi geç tanı konulması nedeniyle halen ülkemizde önemli bir ortopedik sorun olmaya devam etmektedir. Erken tedavi edilmediğinde GKD'nin prognozu kötüleşmekte ve hastalık hayat boyu hastanın hayatını etkileyecek düzeye gelebilmektedir. Yürüme çağına kadar tanısı gecikmiş hastalarda artık yalnız başına kalçayı redükte etmek yeterli olmamakta asetabulumdaki yetmezliğe de müdahale etmek gerekmektedir. Asetabulumdaki bu anterolateral yetmezliğe müdahale ederek asetabulumu derinleştirmek amaciyla literatürde farklı pelvis osteotomileri tanımlanmıştır. Salter de ilk olarak 1961 yılında 1,5 yaşından büyük çocuklarda uygulanmak üzere kendi innominate osteotomisini tanımlamıştır [5]. Bu teknikte, osteotomi sonrası açık veya kapalı olarak asetabulum simfizis pübis merkezliğinde döndürülerek özellikle defektif olan anterolateral bölgeyi kapatmak amaçlanmaktadır [2]. Başarılı sonuç alınması osteotominin uygun yaşta uygulanması, kalça hareket sınırlarının normal olması, kalça eklem uyumunun olması ve cerrahi deneyime bağlidır [9]. Salter osteotomisi sonrası asetabular indeksteki değişimin ortalama 10 derece olduğu bildirilmiştir [10]. Bizim çalışmamızda en son takip sırasında ölçülen postoperatif asetabular indeks ortalamas1 24,2 (12-32) derece idi. Asetabular indeksteki ortalama düzelme oranımız 13,1 derece olarak bulundu ve bu değer literatür ile uyumlu idi.

Hastanın yaşı tedavi sonucunu etkileyen en birincil faktör olarak kabul edilmektedir. Artan yaşla beraber asetabulumun yeniden şekillenme kapasitesi düşmektedir. Bizim uyguladığımız hastalarda ortalama hasta yaşı 30,7 ay idi. Macnicol en iyi sonucun 30 aylıktan küçük hastalarda aldıklarını bildirmiştir [11]. Moulin ve ark. 24 yıllık takiplerin SİO’yu 2 ile 4 yaş arasında asetabular indeksi 40 dereceden küçük olan hastalara 
uygulanması gerektiğini vurgulamışlardır [12]. Barret [13] 4yaş altı ve Gülman [14] 1,5 ile 4 yaş arası hastalarda en iyi sonucun alındığını bildirmişlerdir. Bizim çalışmamızda da hasta grubu bu yaş sınırları içinde idi. Belirli bir yaşın altında da kemik kalitesinin yetersizliği nedeniyle SİO tedavide kullanılmamaktadır. Çok ileri yaşlarda osteotomi sonrası asetabulum rekonstrüksiyonunun yeterince yapılamaması ve kalça hareketleri olarak beklentileri karşılamaması gibi istenmeyen sonuçlara neden olabilir [15].

Redislokasyon cerrahi sonrası önemli komplikasyonlardandır. Çalışmamızda 1 kalçada $(\% 1,9)$ redislokasyon gördük. Redislokasyon ve resubluksasyon oranları, Salter ve Dubos'un serisinde \%19,9; Gallien ve ark.'nın $[2,16]$ serisinde \% 18,0 'dır. Osteotominin uygun teknikte yapılması, kapsülorafinin yeterli yapılması, kalça ekleminin uyumunun iyi olması, deneyim ve erken yaş redislokasyon oranının etkileyen faktörler olarak tanımlanmıştır [15]. Teknikte, greftin tespiti için kullanılan Kirschner telinin eklem içine veya dışarıya doğru migrasyonunun literatürdeki oranı \%0,6-10 arasında değişmektedir [17]. Greftin kayması veya kırılması sıklıkla immobilizasyona baglı osteoporoza sekonder olarak ya da Kirschner telinin erken çıkarılması nedeniyle ortaya çıkmaktadır. Çalışmamızda söz konusu komplikasyona rastlamadık. Ancak literatürde bu oran \%0,3-4 arasında tanımlanmıştır [17]. Şenaran ve ark. [18] iki adet K teli ile fiksasyonun sonuçlarının daha iyi olduğunu, Eren ve ark. [19] osteotomi hattının horizontal yerine oblik yapılması ile K teli kullanımına gerek kalmadığını bildirmişlerdir. Biz de tüm vakalarda daha iyi bir tespit olduğunu düşündüğümüz için ve greft rotasyonunun önlemek amaciyla rutin olarak 2 adet $\mathrm{K}$ ile fiksasyon uyguladik.

GKD tedavisinde AVN, tedavi sonuçlarını kötü yönde etkileyebilen bir sorun olarak karşımıza çıkmaktadır. Farklı osteotomi teknikleri ve değerlendirme kriterlerindeki farklılıklardan dolayı tam bir karşılaştırma yapılması zordur. Bu nedenle AVN oranları farklı serilerde \%7-64 arasında değişen farklı insidanslar bildirilmiştir [20-22] (Tablo VII). Bu çalışmaya alınan 51 kalçanın 9 (\%17,6)'unda AVN saptandı (6'sı Tip I, 2'si Tip 2 ve 1'i Tip III). Bu 9 olgunun tümü serinin ortalama yaşının üzerinde olduğu görüldü. Salter ve Dubos AVN'nin pelvik osteotominin değil, açı redüksiyonun bir komplikasyonu olduğunu savunmuşlardır [2]. Açık redüksiyon dışında daha önce uygulanan konservatif tedavi girişimleri, olgunun yaşı, aşırı zorlayıcı pozisyonlarda immobilizasyon AVN oluşumunda etkilidir [23]. AVN oranları Salter ve Dubos'un serilerinde \%6,0; Hansson ve ark.nın serisinde \%21,0'dır $[2,24]$. Ülkemizde yapılan çalışmada bu oran, Gülman ve ark.nın serilerinde \%34 olarak saptamıştır [14]. AVN oranı üzerinde, SİO öncesi açık veya kapalı redüksiyon gibi cerrahi veya Pavlik bandajı gibi konservatif tedavi öyküsünün etkili olduğu düşünülmektedir. Teknik olarak açık redüksiyon ve kapsülorafinin SİO ile birlikte dikkatli bir şekilde uygulanması gerektiğidir. Ameliyat öncesi dönemde traksiyon uygulanması konusu literatürde tartışmalı olup uygulanmasının gerekli olduğunu bildirenler olduğu gibi traksiyonun osteoporoza neden olduğu ve avasküler nekroz riskini arttırdığını bildirenler de olmuştur [25]. Çalışmamızda, ameliyat öncesi traksiyon yapılmamış olmasının hasta grubumuzdaki sonuçlara olumsuz bir etki oluşturmadığı izlenmiştir.

Diğer komplikasyonlar açısından bakıldığında üç vakada $(\% 5,8)$ yüzeyel enfeksiyona rastladık. Enfeksiyon oranı Salter ve Dubos'un serilerinde \%1,5 olarak bildirilmiştir [2]. Çalışmamızda, $5(\% 9,8)$ olguda hareket kısıtll11 ğı bulundu. Bu olgularda da takip süreleri ortalamanın altındaydı. Özellikle cerrahi sırasında yumuşak dokulara özen gösterilmesi ve immobilizasyon süresinin çok uzun tutulmaması hareket kısıtlılığı üzerinde etkili olduğu bildirilmiştir. Alçı ile immobilizasyon süresinin kısa tutulması gelişebilecek osteoporozu ve buna bağlı femur kırığı riskini düşürmede etkilidir [15].

Sonuçta radyolojik olarak 26 (\%51) olguda mükemmel, 15 (\%29) olguda iyi, 8 (\%15) olguda yeterli, 2 (\%4) olguda kötü sonuç tespit edilirken; klinik olarak da 43 (\%84) olguda mükemmel, 7 (\%14) olguda iyi ve $1(\% 2)$ olguda ise kötü sonuç elde edildiği görüldü. Gülman ve ark.nın serilerinde klinik olarak \%79, radyolojik olarak ta \%71 oranında iyi ve mükemmel sonuç elde ettiklerini bildirmiştir [14]. Literatür 
incelendiğinde Salter ve Dubos [2] \%93,6, Roth ve ark. [26] \%100, Klisic ve Jankovic [27] \%63, Macnicol ve Bertol [11] \%69, Zadeh [21] \%86, Berkeley ve ark. [28] \%100, Bohm ve Brzuske [29] \%69, Kapukaya [30] \%80 ve Ağuş ve ark. [31] \%91 çok iyi ve iyi sonuç bildirmişlerdir. Kliniğimizde elde edilen sonuçların literatürle uyumlu olduğu görülmektedir.

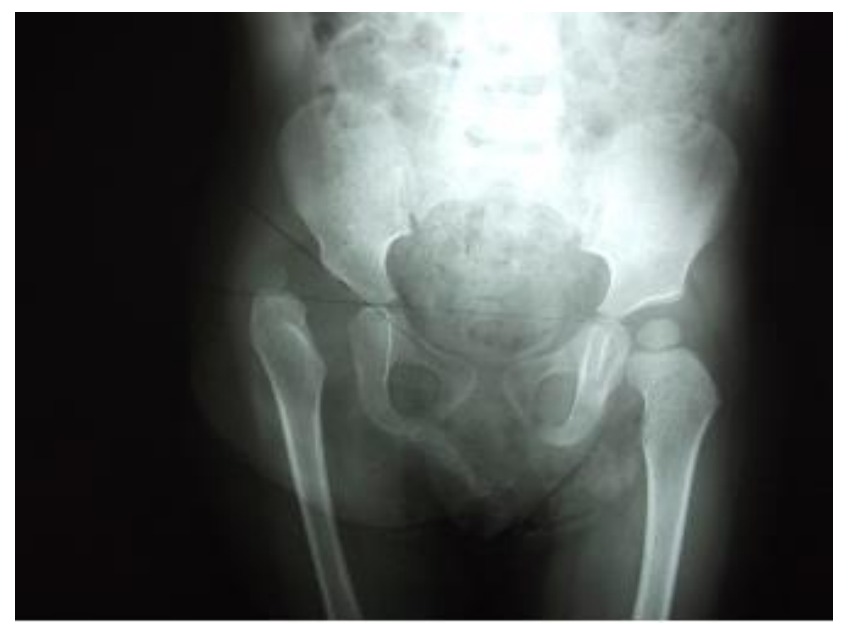

Resim 1. Yirmi iki aylık GKD preoperatif grafi.

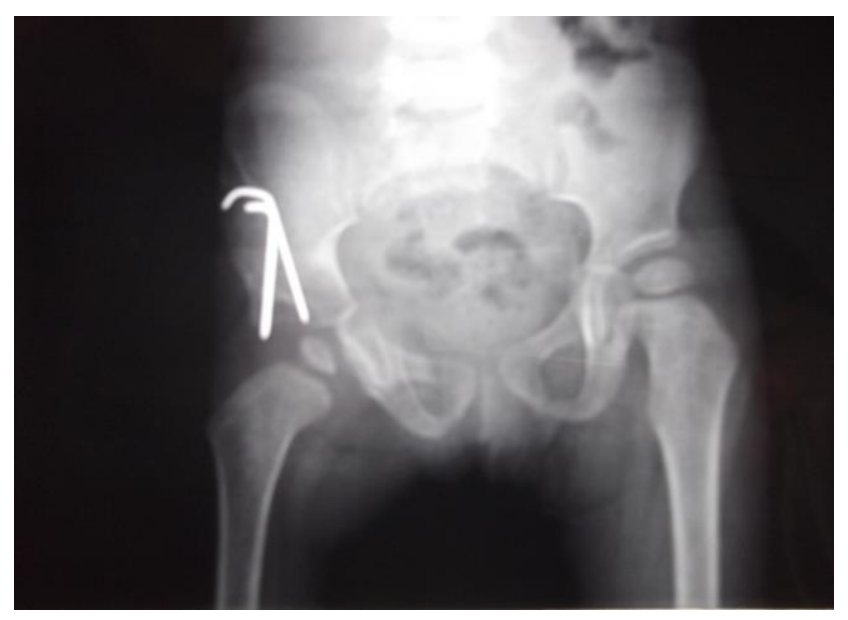

Resim 2. Erken postoperatif grafi.

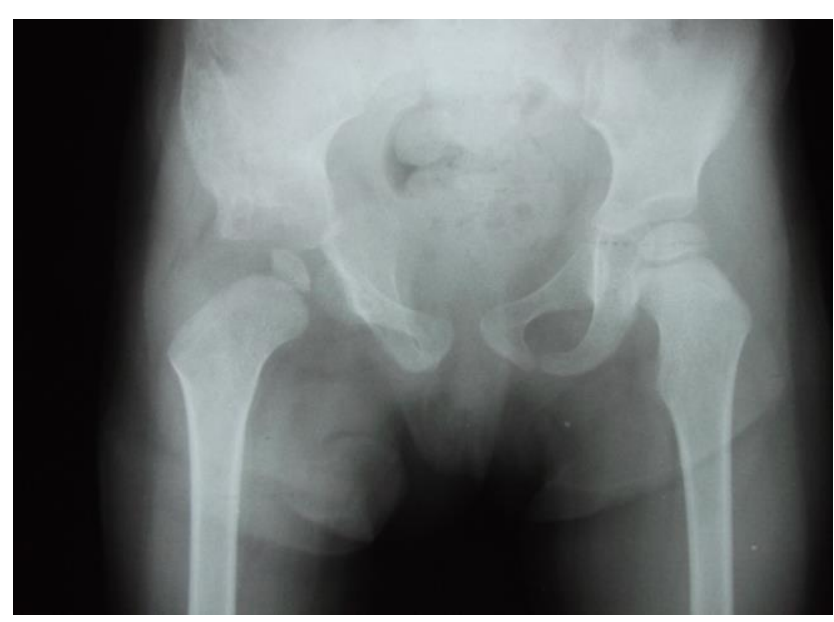

Resim 3. Postop 36. aydaki grafi. 
Son kontrol asetabuler indeks ortalamas $124,2^{0}$ dir. Özçelik ve ark. [32] yaptıkları çalışmada 5-11 yaş asetabular indeks ortalamasını 12,9 $\pm 4,5^{0}$ olarak bulmuşlar ve üst sınırı $22^{0}$ olarak yorumlanmışlardır. Çalışmamızda ulaşılan sonuç bu değerlerle uyumlu olarak bulunmuştur.

GKD'de uygulanan pelvik osteotomiler arasında önemli bir yer tutan Salter innominat osteotomisi prensiplerine uygun davranıldığında özellikle küçük yaş grubunda iyi klinik ve radyolojik sonuçlara ulaşılabilmesine olanak tanımaktadır.

\section{Referanslar}

1. Songur M, Akel I, Karahan S, Kuzgun U, Tümer Y. Prevalence of untreated hip dislocation in Turkish children aged 6 months to 14 years. Acta Orthop Traumatol Turc 2011; 45: 215-20.

2. Salter RB, Dubos JP. The first fifteen year's personal experience with innominate osteotomy in the treatment of congenital dislocation and subluxation of the hip. Clin Orthop Relat Res. Jan-Feb 1974; 72-103.

3. Senaran H, Bowen JR, Harcke HT. Avascular necrosis rate in early reduction after failed Pavlik harness treatment of developmental dysplasia of the hip. J Pediatr Orthop. Mar 2007; 27: 192-7.

4. Salter RB, Kostuik J, Dallas S. Avascular necrosis of the femoral head as a complication of treatment for congenital dislocation of the hip in young children: A clinical and experimental investigation. Canadian journal of surgery. Journal canadien de chirurgie. Jan 1969; 12: 44-61.

5. Salter RB. Innominate Osteotomy in the Treatment of Congenital Dislocation and Subluxation of the Hip. J Bone Joint Surg Br 1961; 43: 518-39.

6. McKay DW. A comparison of the innominate and the pericapsular osteotomy in the treatment of congenital dislocation of the hip. Clin Orthop Relat Res. Jan-Feb 1974; 124-32.

7. Severin E. Congenital dislocation of the hip; development of the joint after closed reduction. J Bone Joint Surg Am. Jul 1950; 32: 507-18.

8. Kalamchi A, MacEwen GD. Avascular necrosis following treatment of congenital dislocation of the hip. J Bone Joint Surg Am. Sep 1980; 62: 876-88.

9. Herring JA, Tachdjian MO. Developmental Dysplasia of the Hip. In: Herring JA, ed. Tachdjian's pediatric orthopaedics. 4th ed. Philadelphia: Saunders/Elsevier 2008.

10. Utterback JD, MacEwen GD. Comparison of pelvic osteotomies for the surgical correction of the congenital hip. Clin Orthop Relat Res. Jan-Feb 1974; 104-10.

11. Macnicol MF, Bertol P. The Salter innominate osteotomy: Should it be combined with concurrent open reduction? J Pediatr Orthop B. Nov 2005; 14: 415-21.

12. Moulin P, Morscher E. Long-term results of the Salter pelvic osteotomy. Der Orthopade. Nov 1988; 17: 479-84.

13. Barrett WP, Staheli LT, Chew DE. The effectiveness of the Salter innominate osteotomy in the treatment of congenital dislocation of the hip. J Bone Joint Surg Am. Jan 1986; 68: 79-87.

14. Gulman B, Tuncay IC, Dabak N, Karaismailoglu N. Salter's innominate osteotomy in the treatment of congenital hip dislocation: A long-term review. J Pediatr Orthop. Sep-Oct 1994; 14: 662-6.

15. Tükenmez M, Perçin S, Tezeren G, Cingöz MA. Gelişimsel Kalça Displazisinin Tedavisinde Salter'in Iliyak Osteotomisi Sonuçlarımız. Turkiye Klinikleri 2006; 26: 390-5.

16. Gallien R, Bertin D, Lirette R. Salter procedure in congenital dislocation of the hip. J Pediatr Orthop. Aug 1984; 4: 427-30.

17. Ege R. Kalça cerrahisi ve sorunları. Ankara: Türk Hava Kurumu Basımevi 1996.

18. Senaran H, Karalezli MN, Simsek S, Arazi M, Kapicioglu MI. [Comparison of Kwire fixation methods in terms of stability in Salter iliac osteotomies]. Acta 
Orthop Traumatol Turc 2007; 41: 104-7.

19. Eren A, Pekmezci M, Demirkiran G, Cakar M, Guven M, Yazici M. Modified Salter osteotomy for the treatment of developmental dysplasia of the hip: Description of a new technique that eliminated the use of pins for internal fixation. J Bone Joint Surg Br. Oct 2007; 89: 1375-8.

20. Powell EN, Gerratana FJ, Gage JR. Open reduction for congenital hip dislocation: The risk of avascular necrosis with three different approaches. J Pediatr Orthop. Mar-Apr 1986; 6: 127-32.

21. Zadeh HG, Catterall A, Hashemi-Nejad A, Perry RE. Test of stability as an aid to decide the need for osteotomy in association with open reduction in developmental dysplasia of the hip. J Bone Joint Surg Br. Jan 2000; 82: 17-27.

22. Thomas IH, Dunin AJ, Cole WG, Menelaus MB. Avascular necrosis after open reduction for congenital dislocation of the hip: Analysis of causative factors and natural history. J Pediatr Orthop. Sep-Oct 1989; 9: 525-31.

23. Ogden J. Normal and abnormal circulation. In: Tachdjian MO, ed. Congenital dislocation of the hip. New York: Churchill Livingstone 1982; 798.

24. Hansson G, Althoff B, Bylund P, Jacobsson B, Lofberg AM, Lonnerholm T. The Swedish experience with Salter's innominate osteotomy in the treatment of congenital subluxation and dislocation of the hip. J Pediatr Orthop. Mar-Apr 1990; 10: 159-62.

25. Tonnis D. Surgical treatment of congenital dislocation of the hip. Clin Orthop Relat Res. Sep 1990; 33-40.

26. Roth A, Gibson DA, Hall JE. The experience of five orthopedic surgeons with innominate osteotomy in the treatment of congenital dislocation and subluxation of the hip. Clin Orthop Relat Res. Jan-Feb 1974; 178-82.

27. Klisic P, Jankovic L, Basara V. Long-term results of combined operative reduction of the hip in older children. J Pediatr Orthop. Sep-Oct 1988; 8: 532-4.

28. Berkeley ME, Dickson JH, Cain TE, Donovan MM. Surgical therapy for congenital dislocation of the hip in patients who are twelve to thirty-six months old. J Bone Joint Surg Am. Mar 1984; 66: 412-20.

29. Bohm P, Brzuske A. Salter innominate osteotomy for the treatment of developmental dysplasia of the hip in children: Results of seventy-three consecutive osteotomies after twenty-six to thirty-five years of follow-up. J Bone Joint Surg Am. Feb 2002; 84: 178-86.

30. Kapukaya A, Subaşı M, Necmioğlu S, Kırkgöz T. Gelişimsel kalça çıkıkların cerahi tedavisinde Salter pelvik osteotomisinin sonuçları. Journal of Arthroplasty Arthroscopic Surgery 2000; 11: 156-61.

31. Aguş H, Kalenderer Ö, Pedükcoflkun S, Eryanılmaz G, Resole A. Yürüme sonrası gelişimsel kalça çıkıklarının cerrahi tedavisinde erken prognostik faktörlerin değerlendirilmesi. Acta Orthop Traumatol Turc 1999; 35-9.

32. Ozcelik A, Omeroglu H, Inan U, Ozyurt B, Seber S. Acta Orthop Traumatol Turc 2002; 36: 100-5. 